\title{
Aphasia: Bob, Felicity and I
}

Cite as: CMAJ 2020 March 9;192:E262-3. doi: 10.1503/cmaj.191414

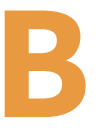

ob sits in front of me with his wife, Felicity. Bob is well-groomed and smells mildly of cigar smoke and urine. His wife is fidgety, nervous.

Bob had a stroke 3 months ago that was caused by a blockage of the left carotid artery. His left temporal lobe, that corrugated communication headquarters of the brain, was hit. The stroke has left him with a weak right leg and arm, and with speech difficulties due to aphasia. He nods as if to say he understands my words, but when I say "Okay, Bob, touch the top of your head with your right hand," he does not understand my instructions.

Bob no longer works as the manager of a large plumbing supply shop. He no longer drives and cannot reliably count change. His wife does the banking now. Felicity says Bob gets very frustrated at times, especially when he cannot get his point across. That is when he may start shaking his fist at her. "I feel a bit frightened sometimes, don't I, dear?," Felicity says, turning to Bob.

In a daydream, I transform myself into a tiny injectable material ... I enter Bob's bloodstream, seeking to reach the area of stroke-related damage, his temporal lobe, and the less-damaged penumbra at its periphery. I want to hear the deep, frightened, quivering voice that is lying within his damaged neurons.

The voice is wailing: "Don't you think I would talk if I could? I hate the large holes in the sentences you utter. I am so sick of the idiotic smiles on the faces of people talking to me. None of you have a clue! You point to objects I know, but the words lie buried too deep for me to dig out. I say 'yes' when I mean 'no,' 'fruck.rud' when I mean 'red truck.' And a wind is blowing from east to west in my head. Sometimes I hear sounds like pine cones being crunched under 300-pound logger's boots. I hate it! I haaaaaaaaaate iiiiiiiit!"

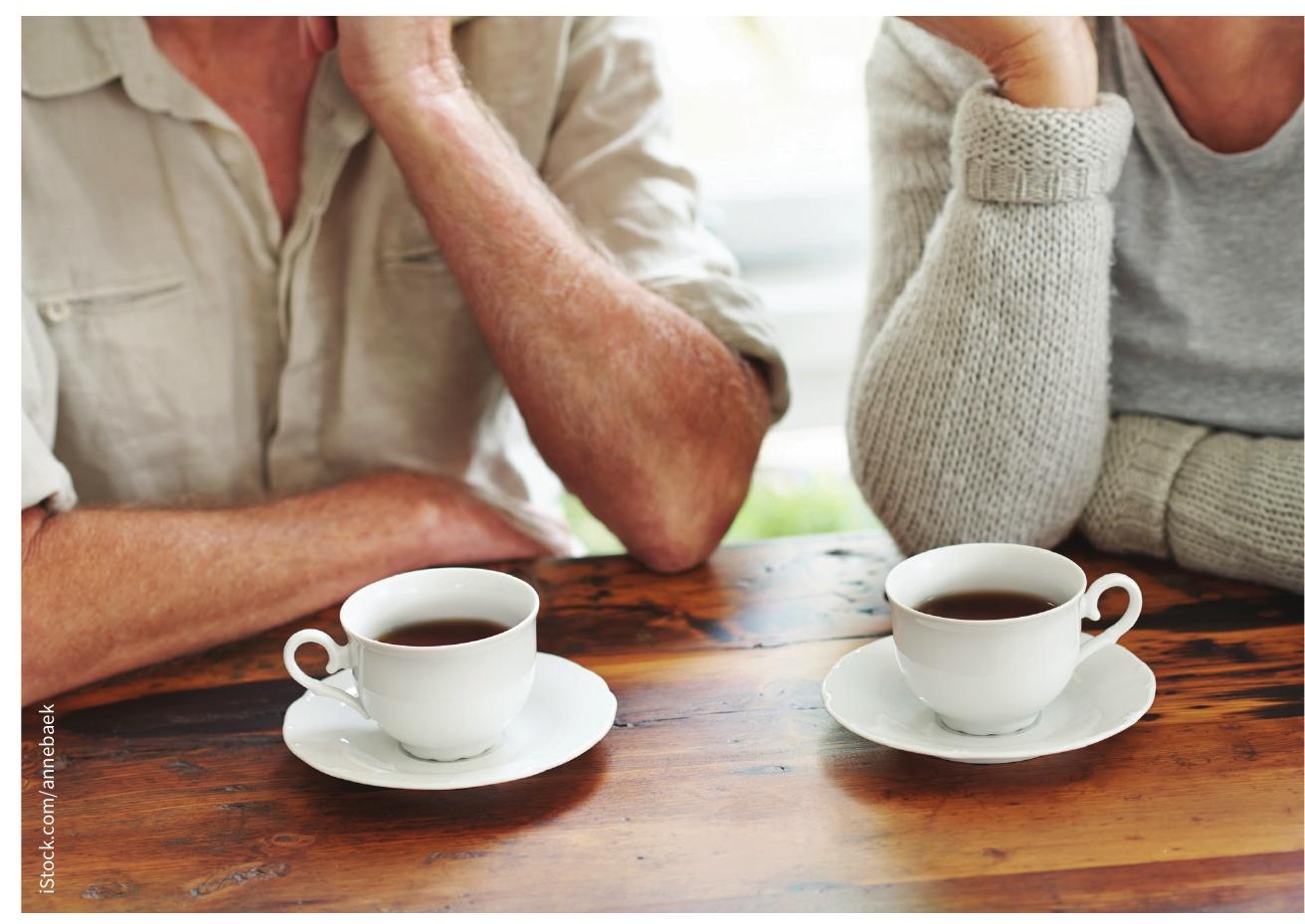

Bob looks restless, irritated. When I ask him "what is the matter?" he stares long and hard at his devoted wife who drove him to his clinic appointment, chose his clothes and made sure he was dressed properly. Sometimes she needs to wipe Bob's bum. What is the meaning behind the stare he fixes on her? He smirks, shrugs.

I try once more: "What's up, Bob? What's bugging you?"

Again, Bob looks toward his wife. "She, she, she, she dun't take."

Aha. "She doesn't talk. Is that what you mean, Bob?"

Felicity frowns, twitches. She is crying now. Thick gluey tears. "What do you mean, I don't talk - you don't talk! And I do so much for you ...." Her voice trails off. Felicity feels overwhelmed and underappreciated.

Is it time to fill out a "lifestyle prescription?"1 Our speech language pathologist has been working hard with Bob and Felicity to practise new drills and develop new habits.
This work has been essential in helping Bob. But stroke can sometimes affect life in ways that are beyond the reach of regular care, leaving patients, families and caregivers frustrated, feeling helpless and lacking in direction. For this reason, my nurse and I have developed lifestyle prescriptions, not for medications but for specific actions that, if performed repeatedly, could lead to change. Sometimes the lifestyle prescription is the best weapon I have in my medical holster. It goes on the refrigerator or a kitchen cabinet so the patient and spouse can refer to it frequently.

The prescription I write for Bob and his wife says: "Talk to each other, slowly. You may need to repeat yourself over and over, phrases, sentences, whatever ... be patient with one another. Try to talk every morning for about 10 minutes to start and slowly build up to 30 minutes of continuous conversation. Have a coffee at the same time."

Felicity and Bob return to my clinic 3 months later. Bob is not talking a blue 
streak, but he is a little calmer and more alert. He speaks more words that make sense. His wife says they sit down in the kitchen each day with a coffee and just talk - about the weather, their kids, finances, their neighbour who refuses to offer a few bucks to fix the fence between their properties. They do not converse the way you and I do, but they are talking. Felicity is learning that she does not have to understand every one of Bob's words to get the gist of what he is saying. She is calmer, too. Aphasia has robbed them of so much, but they realize things could be worse. And they are entering that zone of altered communication where not everything has to be spoken. A zone where ges- tures, or small movements of the head or arms, are full of meaning.

In Bob's brain, I can hear a less frantic voice: "She's listening, wants to know what I think. And even if I say 'fuer' when I mean 'fire,' or 'called cat' when I mean 'cold cuts,' she understands. At last, I'm getting somewhere."

No, I would not choose to be aphasic, but today I see a couple in love. They are holding hands as they walk this new path in their life's journey, perhaps communicating better than they have in years.

\section{Hillel M. Finestone MDCM}

Bruyère Continuing Care; Ottawa Hospital Rehabilitation Centre, Ottawa, Ont.

\section{Reference}

1. Finestone HM, Sohmer J. The lifestyle (LSx) prescription: another use for the pad. CMAJ 2011; 183:2068.

Acknowledgement: I would like to acknowledge the excellent editing of my journalist friend, Paul McKeague. He condensed a longer manuscript and highlighted key material.

This article has been peer reviewed.

Author's note: "Bob" and "Felicity" are not an actual patient and wife but are composites of the many patients and families who I have had the pleasure of treating over the past 25 years as a stroke physiatrist. The "lifestyle prescription" referred to is an actual tool that I have used during the course of my clinical practice. I write on a prescription pad various suggestions that are not actually drug orders. 